\title{
Bending Performance of Cross-laminated Timber- concrete Composite Slabs According to the Composite Method
}

Seung-Youp Baek, Yo-Jin Song, Seok-Hoon Yu, Dong-Hyeon Kim, and Soon-Il Hong *

Bending strength tests were conducted of cross-laminated timber (CLT)concrete composite slabs according to the shear connection method and carbon fiber reinforced plastic (CFRP) reinforcement. The bending strength of the composite slab that was shear-connected with an epoxy adhesive was $17 \%$ higher than that of a composite slab that was shearconnected with a self-tapping screw. In addition, the CLT-concrete slip of the former composite slab was also measured as $20 \%$ lower than the latter under the same load, showing a behavior close to that of a full composite. Both shear connection methods generated a failure in a low loaddeformation section when there was a defect in the outermost tensile laminae of the CLT. In contrast, the CFRP reinforcement in the tension part of the composite slab suppressed the failure at the defect in the outermost tensile laminae. This reinforcement effect increased the reliability of the bending performance of the composite slab by preventing the failure of the composite slab while in a constant failure mode. Furthermore, the slip of the composite slab decreased $49 \%$ after its reinforcement with CFRP, showing a behavior close to that of a full composite.

Keywords: CLT; Timber-concrete composite; Composite; Shear connection; CFRP; Failure mode

Contact information: Department of Forest Biomaterials Engineering, Kangwon National University,

1- Kangwondaehak-gil, ChunCheon-si, Gangwon-do, 24341, Republic of Korea;

* Corresponding author: hongsi@kangwon.ac.kr

\section{INTRODUCTION}

The timber-concrete composite (TCC) first appeared in a bridge in the United States in the 1920s. In Europe, TCC was introduced as an alternative to steel concrete structures due to the lack of steel bars during the Second World War (Rodrigues et al. 2013). Recently, interest in timber, an environment-friendly material, has increased in the construction market, prompted in part by the rising temperature of the earth due to the increase in greenhouse gases, including carbon dioxide (Collins 2020). In particular, the emergence of cross-laminated timber (CLT), which is suitable for high-rise timber structures, is increasing the use of TCC combined with concrete. In the composite fabrication process of TCC, it is crucial to generate full composite behavior for loads by integrating CLT and concrete with different properties. A full composite refers to a case where there is no slip between two materials. When a behavior close to that of a full composite appears, the bending stiffness increases due to the small values of slip and deflection. In contrast, when two materials are not shear-connected, they are called a "no composite." When a behavior close to that of a no composite appears, the bending stiffness decreases due to the occurrence of a large slip and a large deflection (Fragiacomo and Lukaszewska 2011). In the TCC field, a composite fabrication process that shear-connects two materials using a 
physical or chemical method is being researched. Screws are mainly used for the physical connection methods.

In a study by Park and Lee (2019), the maximum load was highest when a shear connector was inserted into a CLT at $90^{\circ}$; a shorter depth of the insertion of the shear connector into the concrete resulted in more concrete failure and the nail pull-out phenomenon occurred (Park and Lee 2019). However, Kim and Kim (2018) found that when the insertion angle was $90^{\circ}$, the lowest maximum shear strength and the slip modulus were obtained, and the shear performance was highest at the insertion angle of $45^{\circ}$. Mai et al. (2018) confirmed that the bending stiffness (EI) of bending specimens was highest and the slip was smallest when the screw insertion angle was $45^{\circ}$. Thus, it has been verified that the bending performance of TCC is highest when the connector insertion angle is $45^{\circ}$. Besides the frequently used screws, steel plates such as mesh plates (Mudie et al. 2019) and hot-galvanized steel plates (Estévez-Cimadevila et al. 2020) have been developed. Furthermore, Lukaszewska et al. (2010) performed various composite fabrication processes, such as insertion of screws in a steel tube, use of ring-shaped nails in steel plates, and insertion of screws in the notch joint and the steel tube. Studies on composite fabrication processes using screws and notches together have also been conducted (Jorge et al. 2010; Jiang and Crocetti 2019). Methods that use adhesives as chemical connectors besides metal shear connectors have also been studied. Brunner et al. (2007) developed a special adhesive that can bond CLT with wet or hardened concrete (Brunner et al 2007). Song et al. (2021) raised the problem of the degradation of the quality of CLT due to the moisture of the concrete when a CLT-concrete composite slab is fabricated with a shear joint, and they found that such problems could be solved using a shear connection method with epoxy adhesive. Excellent single shear performance and bending performance of the structural lumbers are obtained by shear-connected timber and concrete by using a selftapping screw (STS) and epoxy adhesive (Tannert et al. 2020). The bending performance of TCC is being researched according to various compounding methods. However, few studies have been conducted on the slip between CLT and concrete and bending stiffness. Such studies could indicate the full composite performance according to the shear connection method, which is important in composite floor plates. Therefore, differences in the degree of full composite and bending stiffness need to be researched by investigating the slip of TCC slabs according to the shear connection method.

Not only the composite fabrication process using the shear connection method but also methods that attach reinforcements such as fiber-reinforced plastic (FRP) can be used in the composite fabrication process of CLT-concrete composite slabs. Hence, studies have been conducted on the composite fabrication process for CLT and FRP to improve the bending performance of CLT. When the tensile laminae of CLT was reinforced with glass fiber-reinforced plastic sheets, the modulus of elasticity (MOE) and the modulus of rupture (MOR) increased 7\% and 17\% from those of the CLT, respectively (Song and Hong 2018). Furthermore, Song et al. (2019) reinforced CLT with carbon fiber-reinforced plastic (CFRP) in the form of a sheet and a rod. The MOE and MOR of the CLT reinforced with the sheet increased $27 \%$ and $48 \%$ from those of the CLT, respectively, and the MOE and MOR of the CLT reinforced with a rod increased $9 \%$ and $8 \%$ from those of the CLT, respectively. Therefore, it is believed that CLT will show a high bending performance when the tensile laminae of the CLT of a CLT-concrete composite slab is reinforced with a CFRP sheet.

This study also assessed the bending performance of a CLT-concrete composite slab fabricated using the shear connection method and CFRP reinforcement. In addition, 
the bending strength value was predicted using the gamma method and compared with the experimental value.

\section{EXPERIMENTAL}

\section{Materials}

\section{CLT and concrete}

The CLTs were fabricated with domestic Larix kaempferi Carr. laminae. The average air-dry specific gravity of the laminae was $0.54 \pm 0.04$, and the average air-dry moisture content was $12 \pm 1.1 \%$. The MOE of the laminae was measured using a nondestructive method via the natural frequency of the longitudinal vibration, and the measured MOE of the laminae was classified in accordance with KS F 3021 (2013). The MOE of the laminae of the major direction (longitudinal direction) comprising the CLT was $13.1 \mathrm{GPa}$, and the MOE of the transverse direction was $10.7 \mathrm{GPa}$. Phenol-resorcinol formaldehyde (PRF) was used for inter-laminar adhesion by applying $400 \mathrm{~g} / \mathrm{m}^{2}$ of it on one side with 1.0 MPa pressure (Song and Hong 2016). The design strength of the concrete was 24 MP. For the concrete fabrication, Portland cement (Cheonmapyo cement, Sungshin Cement Co., Ltd., South Korea) and coarse aggregates with the maximum size of $25 \mathrm{~mm}$ were used. The water/cement ratio of the concrete for the mix design was 0.43 .

\section{Slab production according to the shear connection method and CFRP reinforcement}

The Type-A specimen was fabricated as a 5-ply CLT with a length of 3,000 mm, a width of $240 \mathrm{~mm}$, and a height of $150 \mathrm{~mm}$ (Figs. 1 and 2). The Type-B specimen was fabricated by pouring wet concrete to up to $60 \mathrm{~mm}$ thick over a $90 \mathrm{~mm}$-thick CLT. Selftapping screw (ASSAY 3.0 SK, Wurth, Germany) was used for the shear connection between the CLT and the concrete. The joint with an STS was designed with an end distance of 18D (D: diameter of the STS), an edge distance of 5D, an 18D space between the rows of bolts, and a 5D space between the bolts in a row (ETA 11/0190 2013). The STSs were inserted in 14 lines of four units at an insertion angle of $45^{\circ}$ (Kim and Kim 2018) and an insertion depth of 10D.
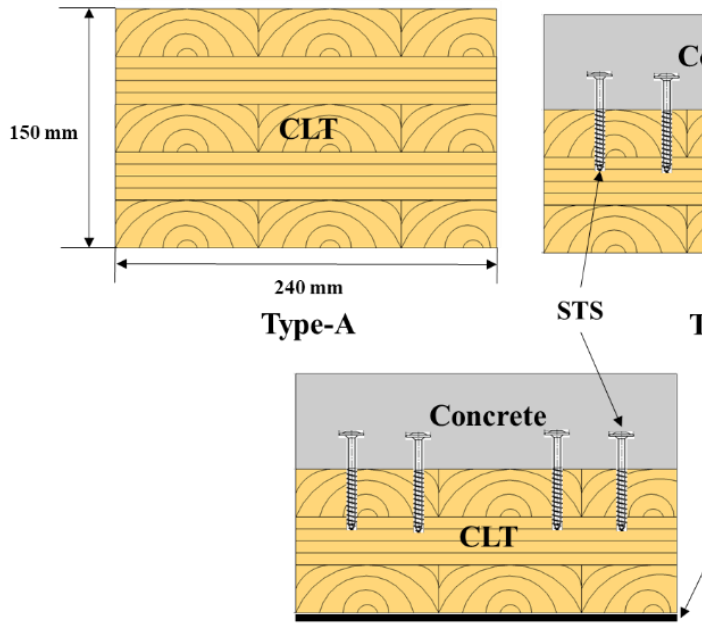

Type-D
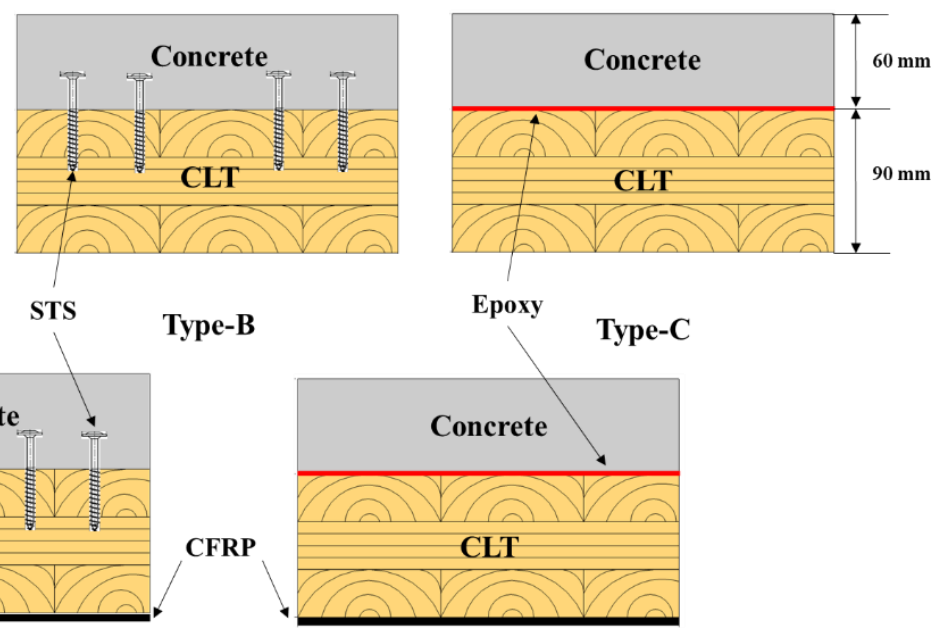

Type-E

Fig. 1. Schematic of specimens using shear connection and CFRP reinforcement (cross-section) 


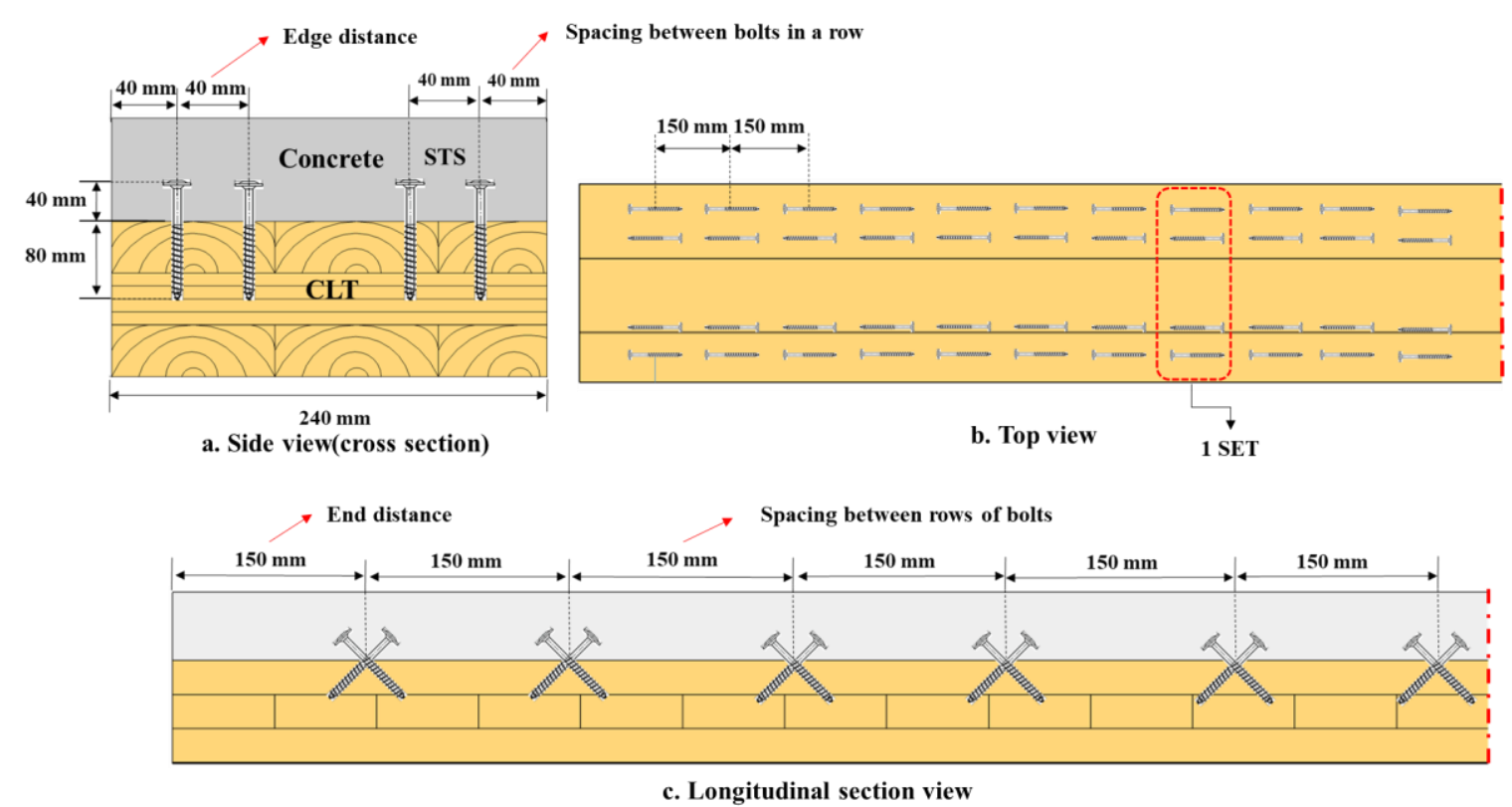

Fig. 2. STS design method and schematics of the specimens in each direction of shearconnected with the STS (Type-B and Type-D)

The Type-C specimen was fabricated by pouring wet concrete to up to $60 \mathrm{~mm}$ thick before the epoxy adhesive (Sikadure 31, Sheet, S. P. D, Sika, Switzerland), which had been applied over the CLT to $1.0 \mathrm{~mm}$ thick, had hardened. The Type-D specimen was fabricated using the same shear connection method as that used for the Type-B specimen, by reinforcing the entire surface of the CLT tensile lamina with a $1.2 \mathrm{~mm}$-thick CFRP sheet (Shinsung Materials, Seoul City, South Korea). The MOE and the tensile strength of the CFRP used were 470,000 and $2557 \mathrm{MPa}$, respectively (Park et al. 2009). A polyurethane adhesive (OTTO COLL P84, Otto, Germany) was used to bond the CLT and the CFRP by applying $300 \mathrm{~g} / \mathrm{m}^{2}$ of it on one side at a pressure of $1.0 \mathrm{MPa}$ (Song et al. 2019). The TypeE specimen was fabricated by shear-connecting the epoxy CLT and the concrete with an adhesive and reinforcing them with CFRP. Two specimens were fabricated for each type. After the concrete was poured, it was cured at room temperature for 40 days.

\section{Methods}

Bending strength test

A bending strength test was performed with a 4-point load in three divisions, as shown in Fig. 3.

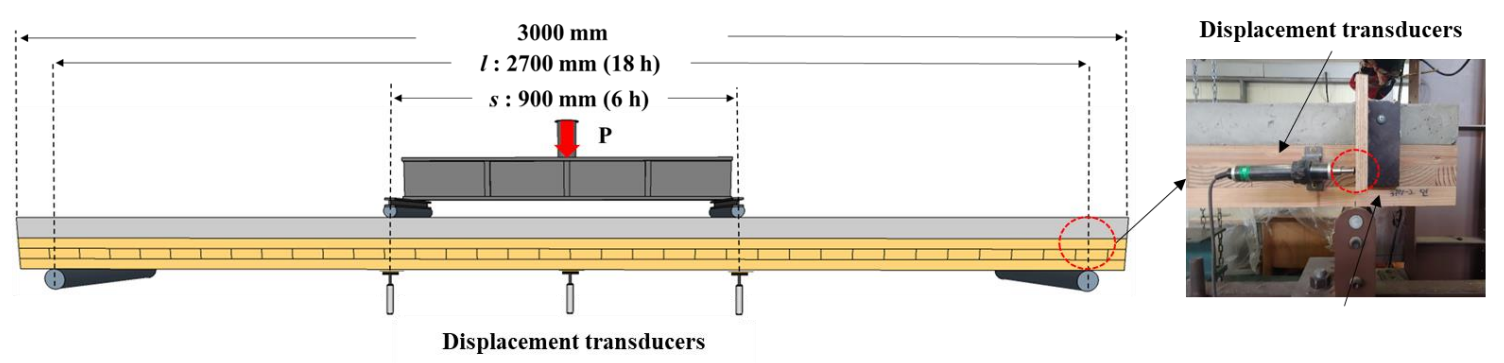

Fig. 3. Set up for bending strength measurement of the slip between the CLT and the concrete 
The span-to-depth ratio was 18:1, the distance between the two loading points was 6 times the depth of the specimen, and the loading rate was $5 \mathrm{~mm} / \mathrm{min}$ as per BS EN 16351 (2015). To measure the deflection of the specimens, displacement meters (CDP-50, Tokyo Sokki Kenkyujo, Tokyo, Japan) with a maximum capacity of $50 \mathrm{~mm}$ were installed at the center of each specimen (global) and at each loading point (local). The slip between the concrete and the CLT was measured using a displacement meter (CDP-25, Tokyo Sokki Kenkyujo, Tokyo, Japan) with a maximum capacity of $25 \mathrm{~mm}$ installed at the CLT after fixing a tip fabricated for slip measurement to the concrete.

\section{RESULTS AND DISCUSSION}

\section{Load-deflection Curve and Failure Mode}

Both specimens of Type-A, a 5-ply CLT, formed a straight-line section in the loaddeformation graph (Fig. 4).
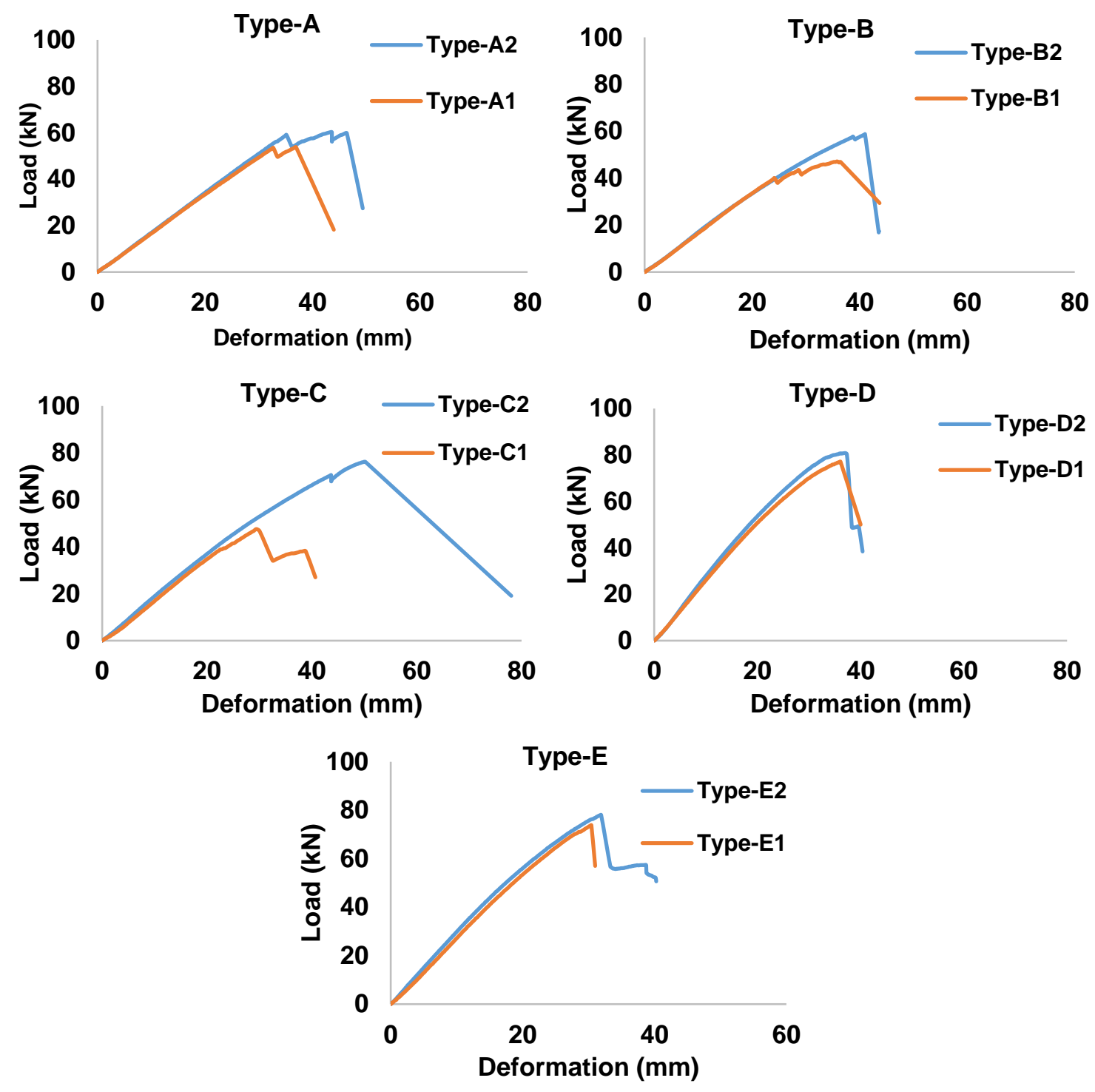

Fig. 4. Load-deflection curves from the static bending test 
Then, as shown in Fig. 5, the first failure occurred in the tensile lamina of the CLT, and the final rolling shear failure occurred in the middle lamina. CLTs are usually fractured at defects such as knots in the outermost tensile lamina or undergo rolling shear failure along the annual ring in laminated timber (Song 2017).

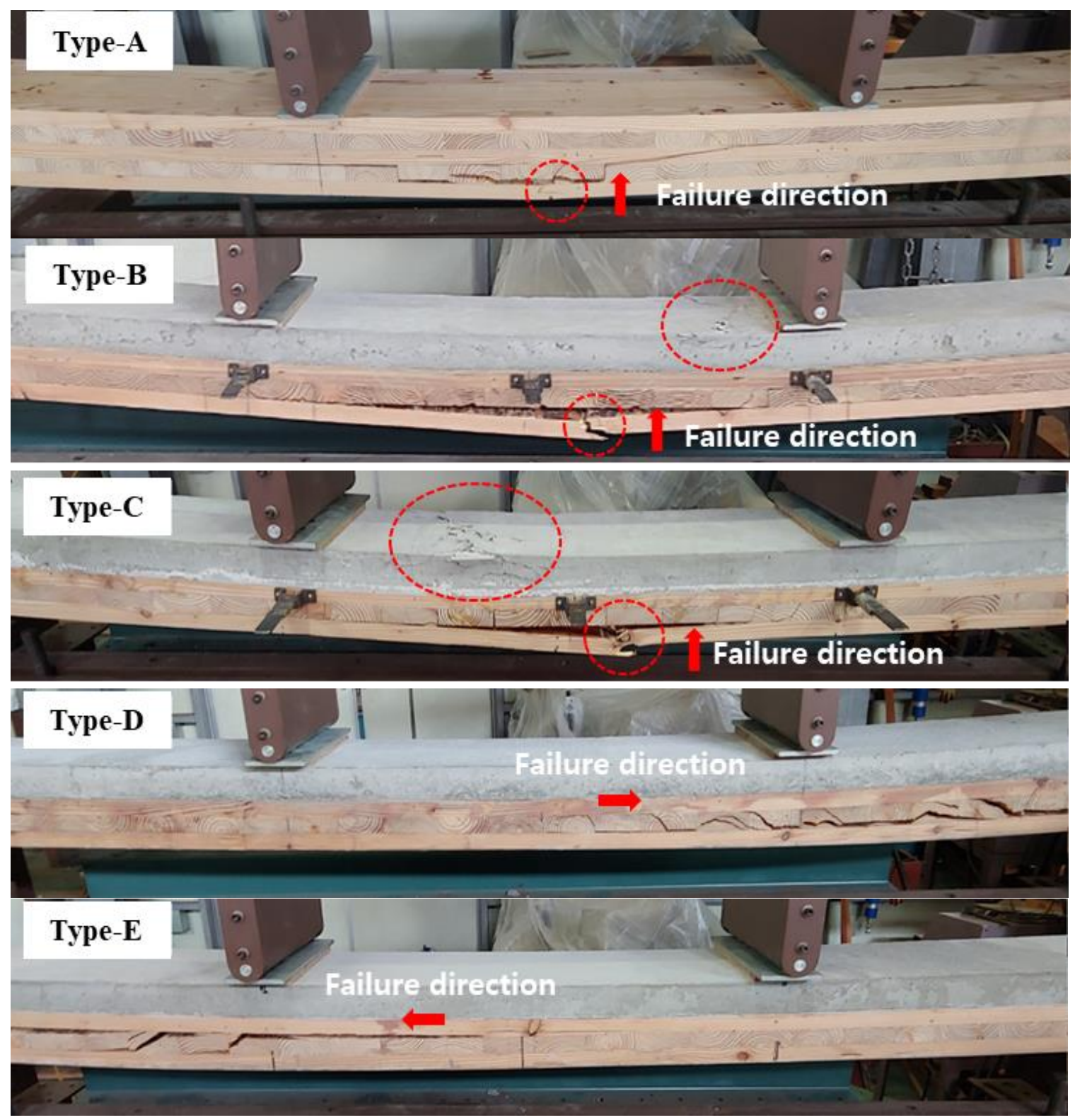

Fig. 5. Photographs of the failure directions and modes of the specimens from the bending strength tests (Type-A: tensile failure, Type-B: tensile failure, Type-C: tensile failure, Type-D: rolling shear failure, and Type-E: rolling shear failure)

It was found that the maximum load of Type-C2 was $76.2 \mathrm{kN}$; thus, it endured the maximum load of the composite floor plate reinforced with CFRP. However, the maximum loads of Type-B1 and Type-C1 were lower by $25 \%$ and $38 \%$ than those of Type-B2 and Type-C2, respectively. The reason for this was the presence of knots in the outermost tensile lamina of Type-B1 and Type-C1 unlike Type-B2 and Type-C2, and failure occurred 
in a low load-strain section due to these knots. Ján Kanócz and others who examined failure mode according to the shear connection method of CLT-concrete composite floor plates also reported that failure occurred in the outermost tensile lamina of CLT regardless of the shear connection method Ján Kanócz 2013, 2014, 2015), particularly at defects such as knots (KQ et al. 2018). These results confirmed that the defects in the outermost tensile lamina of the CLT decreased the bending performance of a composite slab, regardless of the shear connection method.

In contrast, for the reinforced Type-D and Type-E specimens, the tensile failure was suppressed by the CFRP despite the presence of a knot in the outermost tensile lamina, and the specimens had a certain failure mode by the rolling shear through the suppression of the tensile failure.

Unlike the tensile failure of glulam reinforced with CFRP sheets (Glišović et al. 2017), reinforced TCCs are more vulnerable to shear strength rather than tensile failure. Thus, it was found that rolling shear failure occurred along the annual ring of the laminated timber in the direction perpendicular to the fiber. This failure mode decreased the maximum load deviation of the composite slab by a factor of 5. In addition, the maximum load of the slabs reinforced by the CFRP increased $34 \%$ compared to that of the slab that was not reinforced by the CFRP.

Meanwhile, there was no difference of local deflection ratio to the global deflection by the shear connection method of the CLT-concrete composite specimens. The CFRPreinforced slab was less affected by the shear force because the ratio of its local deflection to the global deflection was lower than that of the slab that was not reinforced with CFRP.

Table 1. Bending Test Results

\begin{tabular}{|c|c|c|c|c|c|c|c|c|c|}
\hline \multicolumn{2}{|c|}{ Specimens } & $\begin{array}{c}\text { Moisture } \\
\text { Content } \\
(\%)\end{array}$ & $\begin{array}{l}\text { Max. } \\
\text { Load } \\
(\mathrm{kN})\end{array}$ & $\begin{array}{l}\text { Ave. } \\
\text { M. } \\
\text { Load } \\
(\mathrm{kN})\end{array}$ & $\begin{array}{l}\text { Global } \\
\text { Deflection } \\
(\mathrm{mm})\end{array}$ & $\begin{array}{l}\text { Ave. } \\
\text { Global } \\
\text { Deflection } \\
(\mathrm{mm})\end{array}$ & $\begin{array}{l}\text { Local } \\
\text { Deflection } \\
(\mathrm{mm})\end{array}$ & $\begin{array}{l}\text { Ave. } \\
\text { Local } \\
\text { Deflection } \\
(\mathrm{mm})\end{array}$ & $\begin{array}{c}\text { Global } \\
\text { Deflection } \\
\text { or } \\
\text { Local } \\
\text { Deflection }\end{array}$ \\
\hline \multirow{2}{*}{ Type-A } & 1 & 13.4 & 53.1 & \multirow{2}{*}{56.1} & 36.9 & \multirow{2}{*}{36.0} & 34.2 & \multirow{2}{*}{32.9} & \multirow{2}{*}{1.09} \\
\hline & 2 & 11.5 & 59.1 & & 35.1 & & 31.7 & & \\
\hline \multirow{2}{*}{ Type-B } & 1 & 12.8 & 47.1 & \multirow{2}{*}{53.0} & 35.8 & \multirow{2}{*}{38.4} & 33.3 & \multirow{2}{*}{34.8} & \multirow{2}{*}{1.10} \\
\hline & 2 & 12.5 & 58.8 & & 41.1 & & 36.6 & & \\
\hline \multirow{2}{*}{ Type-C } & 1 & 11.7 & 47.5 & \multirow{2}{*}{61.9} & 29.5 & \multirow{2}{*}{39.8} & 26.9 & \multirow{2}{*}{36.0} & \multirow{2}{*}{1.10} \\
\hline & 2 & 12.6 & 76.2 & & 50.2 & & 45.2 & & \\
\hline \multirow{2}{*}{ Type-D } & 1 & 11.6 & 77.2 & \multirow{2}{*}{78.9} & 36.1 & \multirow{2}{*}{36.1} & 33.7 & \multirow{2}{*}{34.1} & \multirow{2}{*}{1.05} \\
\hline & 2 & 12.3 & 80.7 & & 36.1 & & 34.6 & & \\
\hline \multirow{2}{*}{$\begin{array}{l}\text { Type- } \\
\text { E }\end{array}$} & 1 & 12.9 & 73.8 & \multirow{2}{*}{75.9} & 30.3 & \multirow{2}{*}{31.1} & 28.7 & \multirow{2}{*}{29.4} & \multirow{2}{*}{1.05} \\
\hline & 2 & 10.7 & 78.0 & & 31.9 & & 30.1 & & \\
\hline
\end{tabular}




\section{Bending Performance and Composite Action}

The MOE of Type-B was 2\% higher than that of Type-A, but the MOR of Type-B was 5\% lower than that of Type-A. The MOE and MOR of Type-C were $4 \%$ and $17 \%$ higher than those of Type-B, respectively. The slips under the same load condition were less than $1.0 \mathrm{~mm}$ for both Type-B and Type-C specimens, but the slip of Type- $\mathrm{C}$ was $80 \%$ lower than that of Type-B. The slab that was shear-connected with an epoxy adhesive showed a higher MOR than the slab that was shear-connected with an STS and showed a behavior close to that of a full composite because the slip was low. Joakim Thilén also reported that the slip of the TCC slab was 0.01 to $0.02 \mathrm{~mm}$ in adhesive shear connection and 0.23 to $0.27 \mathrm{~mm}$ in the notch+STS junction. Thus, the adhesive shear connected TCC slab was closer to full composite and its bending stiffness was $12 \%$ higher as well (Joakim 2017).

The average MOE and MOR of the CFRP-reinforced slab were 59\% and $26 \%$ higher than those of the slab that was not reinforced. Song et al. (2019) found that when CLT was reinforced with CFRP sheets, the MOE and MOR increased by $27 \%$ and $48 \%$ compared to CLT, respectively. When the bending performance is compared between the CFRP-reinforced CLT and composite floor plates, the MOR of the CLT-concrete composite floor plate improved greatly owing to the CFRP reinforcement, but the increase rate was lower than that of the single CLT reinforced with CFRP. However, the MOE of the CFRP-reinforced composite floor plate was much higher than that of CLT because the concrete endured compression and the CLT endured tension.

Regarding the slip under the same load condition $(47 \mathrm{kN})$ of the CLT-concrete composite slab that was shear-connected with STS, the slip of the CFRP-reinforced slab was $43 \%$ lower than that of the slab not reinforced with CFRP. Regarding the slip of the slabs that were shear-connected with epoxy adhesive under the same load, the slip of the CFRP-reinforced slab was 55\% lower than that of the non-CFRP-reinforced slab. The slips of the CLT-concrete composite slabs reinforced by CFRP decreased in both shear connection methods, showing a behavior close to that of a full composite. The CLTconcrete composite slab reinforced with CFRP did not show differences in bending performance using the shear connection method. Regarding the slip of the CFRPreinforced CLT-concrete composite slab, the slip of Type-D was 6.3 times higher than that of Type-E. This confirmed that the bending performance also increased as the slip decreased.

Table 2. Bending Properties of the CLT and the CLT-concrete Composite Slabs

\begin{tabular}{|c|c|c|c|c|c|}
\hline Specimens & $\begin{array}{c}\text { MOEGlobal } \\
(\mathrm{MPa})\end{array}$ & $\begin{array}{c}\text { MOELocal } \\
(\mathrm{MPa})\end{array}$ & $\begin{array}{c}\text { MOR } \\
(\mathrm{MPa})\end{array}$ & $\begin{array}{c}\text { Max. Slip } \\
(\mathrm{mm})\end{array}$ & $\begin{array}{c}\text { Slip at 47 kN } \\
(\mathrm{mm})\end{array}$ \\
\hline Type-A & 8,747 & 9,271 & 32.7 & - & \\
\hline Type-B & 8,921 & 9,456 & 30.9 & 0.81 & 0.66 \\
\hline Type-C & 9,269 & 9,829 & 36.1 & 0.16 & 0.13 \\
\hline Type-D & 14,317 & 15,176 & 46.0 & 1.44 & 0.38 \\
\hline Type-E & 14,429 & 15,259 & 44.3 & 0.11 & 0.06 \\
\hline
\end{tabular}

MOEGlobal: Modulus of elasticity determined by the global deflection; MOELocal: modulus of elasticity determined by the local deflection; and MOR: modulus of rupture 


\section{Bending performance prediction design using the Gamma method}

When the CLT and the concrete were shear-connected using STS, $r_{i}=$ $\left[1+\pi^{2} E_{i} A_{i} s / K L^{2}\right]^{-1}$ was used. For the slip modulus of the STS, $31.2 \mathrm{kN} / \mathrm{mm}$ was used, which was measured using the same STS as that in a previous study (Gerber 2016). As for $K, 124.8 \mathrm{kN} / \mathrm{mm}$ was applied, which is the sum of the slip moduli of four STSs, because it was designed with one set of four STSs, as shown in Fig. 3. Furthermore, when the CLT was bonded with other materials using an adhesive, $r_{i}=1$ was applied. In this study, the rolling shear modulus $G_{r}$ was calculated based on the CLT Handbook (Gagnon and Pirvu 2011). For the reference bending strength $\left(F_{\mathrm{b}}\right)$ value in the bending moment design, 50 MPa was used (Hwang et al. 2011).

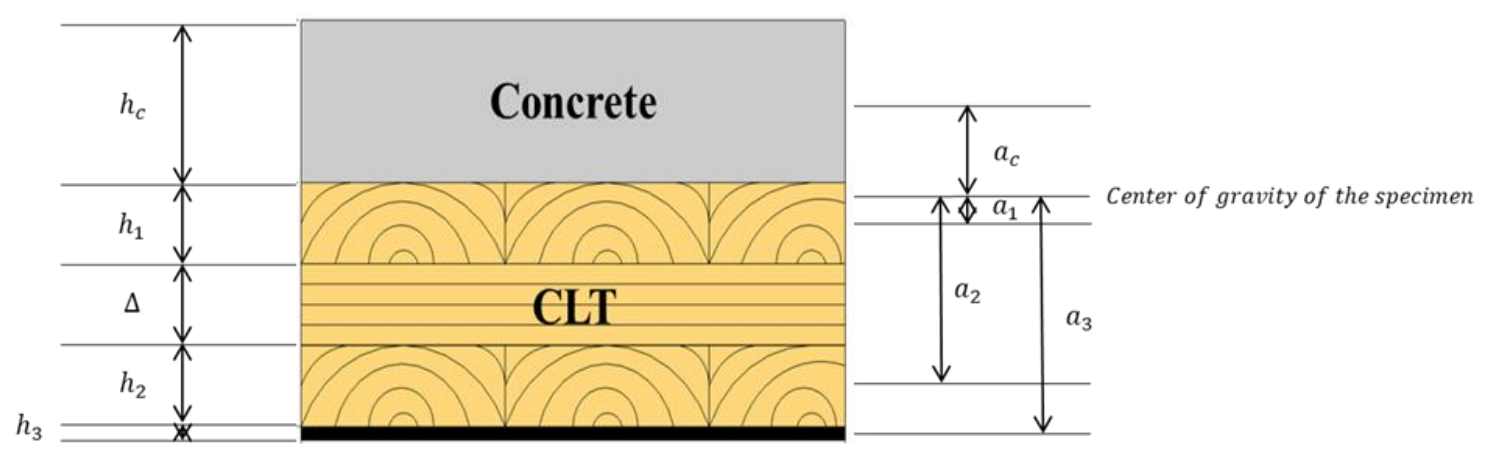

Fig. 6. Cross-section of the CLT-concrete composite slab reinforced with CFRP

Bending stiffness $(E I)$ was calculated according to Eq. 1,

$$
E I_{\text {eff }}=\sum\left(E_{\mathrm{i}} I_{\mathrm{i}}+\gamma_{\mathrm{i}} E_{\mathrm{i}} A_{\mathrm{i}} a_{\mathrm{i}}^{2}\right)
$$

where $E I_{\text {eff }}$ is bending stiffness (EI) by the Gamma method $\left(\mathrm{kN} \cdot m^{2}\right) ; E_{\mathrm{i}}$ denotes MOE of the panel $(\mathrm{MPa}) ; I_{\mathrm{i}}$ is effective moment of the inertia of layer I $\left(\mathrm{mm}^{4}\right) ; I$ is geometrical moment of the inertia $\left(\mathrm{mm}^{4}\right) ; A$ represents cross-section $\left(\mathrm{mm}^{2}\right) ; h_{\mathrm{i}}$ stands for thickness of layer $\mathrm{i}(\mathrm{mm}) ; a_{\mathrm{i}}$ is the distance between the central axis of each panel (mm); and $\gamma$ denotes connection efficiency factor $(0<\gamma \leq 1)$;

Distance between the central axis of each panel $\left(\boldsymbol{a}_{\boldsymbol{i}}\right)$ was calculated according to Eqs. 2 through 5,

$$
\begin{aligned}
& a_{c}=\frac{h_{c}+h_{1}}{2}-a_{1} \\
& a_{1}=\frac{r_{c} E_{c} A_{c}\left(\frac{h_{c}}{2}+\frac{h_{1}}{2}\right)-r_{2} E_{2} A_{2}\left(\frac{h_{2}}{2}+\frac{h_{1}}{2}+\triangle\right)}{\sum r_{i} E_{i} A_{i}} \\
& a_{2}=a_{1}+\frac{h_{1}}{2}+\frac{h_{2}}{2}+\triangle a_{1} \\
& a_{3}=a_{2}+0.6+\frac{h_{2}}{2}
\end{aligned}
$$

where $\Delta$ is thickness of transverse layer $(\mathrm{mm})$.

The factor $\gamma$ is depend on the shear behavior of transverse layer and can be expressed as Eq. 6, 


$$
\gamma_{i}=\frac{1}{1+\pi^{2} \frac{E_{i} A_{i} \Delta}{l^{2} G_{r} b}}
$$

where $G_{\mathrm{r}}$ is rolling shear modulus ( $\left.\mathrm{MPa}\right) ; l$ is span (mm)

Bending moment $(M)$ was calculated according to Eq. 7 ,

$$
M=\emptyset \cdot f_{b} \cdot \frac{(E I) \text { eff }}{E_{\mathrm{i}}\left(\gamma_{\mathrm{i}} a_{\mathrm{i}}+0.5 h_{\mathrm{i}}\right)}
$$

where $\phi$ is resistance factor $(0.9)$; and $f_{\mathrm{b}}$ represents bending strength $(\mathrm{MPa})$.

The difference between the bending stiffness value predicted by the Gamma method and the measured value was $4.3 \%$ on average, and the maximum prediction error was $7.9 \%$. Type-B and Type-C showed measured values higher than predicted values. As for Type-D to Type-E, the predicted values were lower than the measured values. The average difference between the predicted and measured values of the bending moment was 7.0\%. Both Type-B and Type-C not reinforced with CFRP showed high measured values. Type $\mathrm{C}$ showed an error of $14.6 \%$ and the measured values were higher. It seems that the maximum load of Type-C2 was measured high, resulting in a large difference between predicted and measured values. In the case of the CFRP-reinforced composite floor plates, different values were predicted depending on the shear connection method. The maximum bending moment of Type-D was higher than the predicted value, but the predicted value was higher than the measured value for Type-E.

Table 3. Comparison of the Predicted and Measured Bending Performance Values

\begin{tabular}{|c|c|c|c|c|c|c|}
\hline Specimens & $\begin{array}{c}E /_{\text {Test }} \\
\left(\mathrm{kNm}^{2}\right)\end{array}$ & $\begin{array}{c}E l_{\text {Gamma }} \\
\left(\mathrm{kNm}^{2}\right)\end{array}$ & $\begin{array}{c}E l_{\text {Gamma }} / E /_{\text {Test }} \\
(\%)\end{array}$ & $\begin{array}{c}M b_{\text {Test }} \\
(\mathrm{kNm})\end{array}$ & $\begin{array}{c}M b_{\text {Gamma }} \\
(\mathrm{kNm})\end{array}$ & $\begin{array}{c}M_{\text {Gamma }} / M_{\text {Test }} \\
(\%)\end{array}$ \\
\hline Type-A & 590 & 585 & -0.9 & 28.0 & 30.5 & 8.9 \\
\hline Type-B & 602 & 610 & 1.3 & 26.5 & 26.1 & -1.6 \\
\hline Type-C & 625 & 672 & 7.5 & 30.9 & 26.5 & -14.6 \\
\hline Type-D & 966 & 890 & -7.9 & 39.5 & 37.3 & -5.6 \\
\hline Type-E & 974 & 937 & -3.8 & 38.0 & 39.7 & 4.4 \\
\hline
\end{tabular}

E/Test: Bending stiffness determined by the static bending test; ElGamma: Bending stiffness determined by the Gamma method; Mbtest: Bending moment determined by the static bending test; and MbGamma: Bending moment determined by the gamma method

\section{CONCLUSIONS}

1. The modulus of elasticity (MOE) of the cross-laminated timber- (CLT)-concrete composite slab that was shear-connected with epoxy adhesive did not remarkably vary from that of the slab connected with self-tapping screw (STS), but the modulus of rupture (MOR) of the former was somewhat high and the slip between the CLT and the concrete was low. Hence, it showed a behavior close to that of a full composite.

2. When there was a knot in the outermost tensile lamina of the CLT, the slab failed in the low load-deformation section regardless of the shear connection method, which resulted 
in a large strength deviation.

3. The failure of the CLT-concrete composite slab reinforced with carbon fiber reinforced plastic (CFRP) was suppressed by the CFRP even when there was a defect in the outermost tensile lamina. As a result, it showed a constant failure mode from the rolling shear and a low strength deviation.

4. The values of the bending stiffness predicted by the Gamma method were almost consistent, but the predicted values of the bending moment were not consistent due to large errors.

\section{ACKNOWLEDGEMENTS}

This study was conducted with the support of "R\&D" Program for Forest Science Technology (Project No. 2019151D10-2023-0301) provided by Korea Forest Service (Korea Forestry Promotion Institute).

\section{REFERENCES CITED}

Brunner, M., Romer, M., and Schnüriger, M. (2007). "Timber-concrete-composite with an adhesive connector (wet on wet process)," Materials and Structures 40(1), 119126. DOI: $10.1617 / \mathrm{s} 11527-006-9154-4$

BS EN 16351 (2015). "Timber structures - Cross laminated timber - Requirements," The British Standards Institution, London, UK.

Collins, L. (2020). Timber-Concrete Composite: An Alternative Composite Floor System, Ph.D. Dissertation, Kansas State University, Manhattan, KS, USA.

Estévez-Cimadevila, J., Otero-Chans, D., Martín-Gutiérrez, E., and Suárez-Riestra, F. (2020). "Testing of different non-adherent tendon solutions to reduce short-term deflection in full-scale timber-concrete-composite T-section beams," Journal of Building Engineering 31, Article ID 101437. DOI: 10.1016/j.jobe.2020.101437

ETA 11/0190 (2013). "Würth self-tapping screws," European Technical Approval, German Institute for Building Technology, Queen Chelsea, Germany.

Fragiacomo, M., and Lukaszewska, E. (2011). "Development of prefabricated timberconcrete composite floor systems," Proceedings of the Institution of Civil EngineersStructures and Buildings 164(2), 117-129. DOI: 10.1680/stbu.10.00010

Gagnon, S., and Pirvu, C. (2011). CLT Handbook: Cross-laminated Timber, FPInnovations, Quebec City, Canada.

Gerber, A. R. (2016). Timber-Concrete Composite Connectors in Flat-Plate Engineered Wood Products, Ph.D. Dissertation, University of British Columbia, British Columbia, Canada. DOI: 10.1061/9780784479117.201

Glišović, I., Pavlović, M., Stevanović, B., and Todorović, M. (2017). "Numerical analysis of glulam beams reinforced with CFRP plates," Journal of Civil Engineering and Management 23(7), 868-879. DOI: 10.3846/13923730.2017.1341953

Hwang, K. H., Park, J. S., and Park, M. J. (2011). Evaluating Structural Performance of Graded Domestic Softwood Lumber, Korea Forest Research Institute, Korea Forest Service, Seoul, Korea.

Jiang, Y., and Crocetti, R. (2019). "CLT-concrete composite floors with notched shear 
connectors," Construction and Building Materials 195, 127-139. DOI:

10.1016/j.conbuildmat.2018.11.066

Jorge, L., Habenbacher, J., and Dujic, B. (2010). “Timber-concrete composite systems with cross-laminated timber," in: Proceedings of $10^{\text {th }}$ World Conference of Timber Engineering (WCTE), Trentino, Italy, pp. 1-8. DOI: 10.3403/bsiso16696

Kim, K. T., and Kim, J. H. (2018). "Load bearing capacity of CLT-concrete connections with inclined screws," Journal of the Architectural Institute of Korea Structure and Construction 34(4), 3-13. DOI: 10.5659/JAIK_SC.2018.34.4.3

KS F 3021 (2013). "Structural glued laminated timber - The Ministry of Knowledge Economy," Korean Agency for Technology and Standards, Seoul, Korea.

Lukaszewska, E., Fragiacomo, M., and Johnsson, H. (2010). "Laboratory tests and numerical analyses of prefabricated timber-concrete composite floors," Journal of Structural Engineering 136(1), 46-55. DOI: 10.1061/(asce)st.1943-541x.0000080

Mai, K. Q., Park, A., Nguyen, K. T., and Lee, K. (2018). "Full-scale static and dynamic experiments of hybrid CLT-concrete composite floor," Construction and Building Materials 170, 55-65. DOI: 10.1016/j.conbuildmat.2018.03.042

Mudie, J., Sebastian, W. M., Norman, J., and Bond, I. P. (2019). "Experimental study of moment sharing in multi-joist timber-concrete composite floors from zero load up to failure," Construction and Building Materials 225, 956-971. DOI: 10.1016/j.conbuildmat.2019.07.137

Park, A. R., and Lee, K. (2019). "Experimental and analytical study of shear connectors for the CLT-concrete composite floor system," Journal of the Korean Association for Spatial Structures 19(1), 65-73. DOI: 10.9712/KASS.2019.19.1.65

Park Jun-Chul, Shin Yoon-Jong, and Hong, S. I. (2009). "Bending performance of glulam beams reinforced with carbon fiber-reinforced plastics bonded with polyvinyl acetatebased adhesive," J. Korean Wood Science and Technology 37(4), 364-371.

Rodrigues, J. N., Dias, A. M., and Providência, P. (2013). "Timber-concrete composite bridges: State-of-the-art review," BioResources 8(4), 6630-6649. DOI:

10.15376/biores.8.4.6630-6649

Song, Y. J., Baek, S. Y., Lee, I. H., and Hong, S. I. (2021). "Variations of moisture content in manufacturing CLT-concrete composite slab using wet construction method," BioResources 16(1), 372-386. DOI: 10.15376/biores.16.1.372-386

Song, Y. J., and Hong, S. I. (2016). "Evaluation of bonding strength of larch crosslaminated timber," Journal of the Korean Wood Science and Technology 44(4), 607615. DOI: 10.5658/WOOD.2016.44.4.607

Song, Y. J., and Hong, S. I. (2018). "Performance evaluation of the bending strength of larch cross-laminated timber," Wood Research 63(1), 105-115.

Song, Y. J., Lee, I. H., Song, D. B., and Hong, S. I. (2019). "Evaluation of delamination and bending performance of composite CLT reinforced with CFRP," Wood and Fiber Science 51(4), 1-10. DOI: 10.22382/wfs-2019-034

Tannert, T., Gerber, A., and Vallee, T. (2020). "Hybrid adhesively bonded timberconcrete-composite floors," International Journal of Adhesion and Adhesives 97, article ID 102490. DOI: 10.1016/j.ijadhadh.2019.102490

Article submitted: April 28, 2021; Peer review completed: July 3, 2021; Revised version received and accepted: September 17, 2021; Published: October 22, 2021.

DOI: $10.15376 /$ biores.16.4.8227-8238 